\title{
How Will the Cost Change after Transformation in Public Nature-Based Attractions? A Framework and Case Study
}

\author{
Jun-Ya Liu ${ }^{1, *(1)}$, Qun-Ji Li ${ }^{2}$, Gary Sigley ${ }^{3}$ and Hua Quan ${ }^{4}$ \\ 1 College of Business, Shanghai University of Finance and Economics, Shanghai 200433, China \\ 2 School of History, Culture and Tourism, Huaiyin Normal University, Huai'an 223300, China; \\ liqunji@163.sufe.edu.cn \\ 3 Faculty of Geographic Sciences, Beijing Normal University, Beijing 100875, China; gary.sigley@bnu.edu.cn \\ 4 School of Convention and Exhibition and Tourism, Shanghai University of International Business and \\ Economics, Shanghai 201620, China; shhqhua@163.com \\ * Correspondence: Liujunya613@hotmail.com
}

Citation: Liu, J.-Y.; Li, Q.-J.;

Sigley, G.; Quan, H. How Will the

Cost Change after Transformation in Public Nature-Based Attractions? A Framework and Case Study. Sustainability 2021, 13, 6468. https:// doi.org/10.3390/su13116468

Academic Editor: Carlos

Oliveira Cruz

Received: 11 April 2021

Accepted: 4 June 2021

Published: 7 June 2021

Publisher's Note: MDPI stays neutral with regard to jurisdictional claims in published maps and institutional affiliations.

Copyright: (c) 2021 by the authors. Licensee MDPI, Basel, Switzerland. This article is an open access article distributed under the terms and conditions of the Creative Commons Attribution (CC BY) license (https:// creativecommons.org/licenses/by/ $4.0 /)$.

\begin{abstract}
Financial viability is crucial for public nature-based attractions, especially in the context where many are seeking to transform their business model and goals in order to survive because of the heavy hit by COVID-19 and pressure from Chinese central government policies to lower entrance fees in state-owned attractions. However, there is little literature relating to the relationship between finance and transformation. To fill the gap, the framework "resource-function-transformation-cost" was proposed to explain the relationship between transformation and cost structure change by combining resource-based theory and function analysis. A case study of Shanghai Sheshan National Forest Park (SNFP) tested the framework and further revealed that (a) transformation happened because of the recombination of resources, followed by the change of functions, leading to capital expenditure being more prominent during the early stages and management costs more so in the latter stage. Further, we conclude that the elasticity of the cost structure is low; (b) the structure of functions tended to be stable over the years; and (c) the cost structure of the management, production and business, and tourism and leisure functions did not change much, while that of ecological protection functions changed significantly from capital expenditure to management costs.
\end{abstract}

Keywords: function analysis; cost structure; transformation; resource-based theory; public nature-based attractions; China; national parks

\section{Introduction}

Financial management is very important for the success of attractions [1,2]. Previous studies have focused on revenue [3-5], especially the income generated from entrance fees, because these favor the local economy [6,7], stakeholders [8], and/or social welfare [9]. Researchers, by contrast, have paid less attention to cost [10] due to the difficulty in obtaining complete cost data [8] and the reality of more likely being focused on cash-strapped agencies [11]. Among existing related cost research in public attractions, scholars mainly focus discussion on the cost bearers [8,12], factors affecting operating costs [10,13], and pricing cost [14-18]. Management accounting studies claim that cost structure is closed and relates to a firm's strategy and performance [19-21], which can give practitioners more information about cost. Therefore, a thorough understanding of cost structure is pivotal for the financial viability of public attractions, especially when facing environmental uncertainty [20]. In the context of global tourism transformation, there is a dearth of research on cost structure to help decision makers. This paper seeks to fill that knowledge gap.

From 28 June 2018, China began the implementation of a ticket reduction campaign for state-owned attractions. The policy was formulated by the National Development and Reform Commission in a document titled Guiding Opinions on Improving the Ticket Price 
Formation Mechanism of State-owned Scenic Spots and Lowering the Ticket Price of Key Stateowned Scenic Spots. Subsequently, from 28 September 2018, approximately $60 \%$ of national AAAAA class tourist attractions (the highest class in China) reduced the entrance ticket price across the country as reported by the Ministry of Culture and Tourism [22]. This policy placed significant financial pressure on attractions. In the face of income reduction due to the change in admission policy and government funding tightening $[23,24]$, managers in attractions tended to focus more on cost. In this context, analysis of the cost structure can help managers in public attractions achieve financial viability and local government provide targeted financial support.

However, as these policies were being implemented, the travel and tourism sectors were heavily hit by domestic and global COVID-19 travel restrictions [25]. In order to survive and attract tourists, many attractions have adopted innovative strategies. China is no exception. For example, in order to stand out amongst the crowd of attractions, the Qingtian River Scenic Area located in Henan Province, a national AAAAA class tourist attraction, spent large sums of money introducing short-term and fast-income projects, such as high-end homestays, 3D high-altitude glass bridges, time tunnels, spring rafting, and promotion through video platforms like Tik Tok [26]. In these challenging circumstances, it is even more imperative that we investigate cost-structure management of tourist attractions during times of transformation.

Unfortunately, previous studies on transformation have mainly focused on environmental conditions [27,28], with little attention on tourist attractions themselves [29]. Whilst there is an established theory, the tourist area life cycle (TALC), illustrating the transformation of the overall state of development in a tourist attraction [30,31], it does not provide much information about financial management. Therefore, it is necessary to develop a framework to link transformation and finance in a tourist attraction to fill the gap, which is very helpful for decision makers from government and attractions to make strategic choices. Here, we explore the question in the area of forest parks in China because of their rapid growth and expansion over the last several decades and the increasing demand of people in urban China, with rising incomes and improved transportation, to experience closer contact with nature.

\section{Literature Review}

\subsection{Resource-Based Theory}

In order to explain the relationship between transformation and cost, it is necessary to know why and how the transformation happens. Previous studies indicate that transformation may come about due to technological innovation [28], changes in land use [27], ticket reduction and management system restructuring [8], and so on. Clearly, they do not explain the essence of transformation, but only some of its features. Ontological thinking, emphasizing the object itself, allows us to approach the topic in more depth [32]. Following this logic, we know that nature-based scenic areas are driven by particular site features and the presence of natural resources [33]. Resource-based theory, which considers the importance and uniqueness of the internal resources of an organization, helps us understand the complexity and essence of transformation.

Resource-based theory, as one of the most remarkable theories in strategic management [34-36], can be traced back to 1959 [36]. The central idea of the theory is that firms have resource heterogeneity, which is a source of performance differences between firms $[35,36]$. On this basis, managers manage their firm's resources in order to achieve a competitive advantage [37].

Resources are described in this approach as those controlled by firms to help them improve efficiency and effectiveness. They are an important driver of a firm's decisions about making moves and countermoves [35,38,39]. This approach can be further reduced to two parts: (1) core resources and (2) supporting resources [40]. The core resources are those "fundamental reasons that prospective visitors choose one destination over another" and "to a great extent, destination physiography is the one parameter of core attractiveness 
around which other factors must be creatively developed" [40] (p. 146). Due to its lesser importance, the supporting resources, such as human resources and capital resources, are combined into one category. A nature-based scenic area is driven by particular site and natural resources (ecosystem) [33], which can be called its core resource. Because of its complexity and immeasurability, the ecosystem (the core resource) is explained separately in the next section by introducing a new concept, that is, 'function'.

\subsection{A Function Analysis}

The concept of 'function', first introduced by Hueting (1970) and then incorporated into economic accounting [41,42], is "a useful instrument to merge ecological principles and economic procedures" [43] (p. 108). It is similar to the concept of 'affordance' from objective ontology, explaining the objective and inherent function presented by an objective environment to the actor [29], but is more operational. De Groot advanced the concept in natural ecosystem studies and developed it as a function-evaluation system [44] and function analysis [45]. Using this approach, a complex ecosystem can be converted into a limited number of ecosystem functions [45]. Ecosystem functions are described as "the capacity of natural processes and components to provide goods and services that satisfy human needs, directly or indirectly" [46] (p. 7). De Groot, Wilson, and Boumans (2002) further noted that "each function is the result of the natural processes of the total ecological sub-system" [47] (p. 394). Accordingly, de Groot (2006) concluded that there are five ecosystem functions: regulation (an ecosystem's ability to regulate ecological processes through biogeochemical cycles and biospheric processes), habitat (helping conserve biological and genetic diversity and evolutionary processes through provision of shelter and reproduction habitat), production (from food and raw materials to energy and genetic materials), information (providing reflective, spiritual, cognitive, innovative, and aesthetic information to humans), and carrier (supporting human activities that require space and other mediums) [45].

These five built-in functions can be further converted into three kinds of humanorientated value: ecological (regulation and habitat functions), economic (production functions), and socio-cultural (information and carrier functions). For nature-based scenic areas, four further functions are identified: ecological protection (EP), production and business $(\mathrm{P} \& \mathrm{~B})$, tourism and leisure $(\mathrm{T} \& \mathrm{~L})$, and management $(\mathrm{M})$ functions.

\subsection{Cost Structure}

Cost in this study refers to those costs that can be monetized and measured in tourist attractions. The cost of nature-based attractions was divided into two parts after establishment, management costs and capital expenditure, on the basis of Green's (2012) study [48]. Management costs are those relating to operations that are predictable, such as staff salaries, office expenditures, ongoing maintenance, and daily ecological protection costs. Capital expenditure is those non-recurrent items, such as investing in roads, buildings, and equipment. Cost structure, therefore, is the proportion of each cost to the total cost.

Researchers and practitioners both agree that cost structure is very important to firm performance $[20,21]$. Aligning a firm's cost structure to its strategy and then optimizing the formulation of strategy are two important tasks of strategy cost management [19]. Therefore, a large body of research in the accounting field focuses on a firm's cost structure $[21,49,50]$. Accounting studies show that there are many factors likely to determine the cost structure [49-51]. These factors can alter managerial actions in order to increase the elasticity of the cost structure [20], which helps strengthen a firm's ability to obtain better performance in the future [49]. However, there is little literature on cost structure in tourist attraction studies. For one thing, information about cost structure is viewed as proprietary and unlikely to be disclosed [49]. For another, the importance of cost structure has not been emphasized by researchers and practitioners in tourist attractions. 


\section{Research Framework}

To establish the importance of cost structure in the operation and explain the relationship between cost and transformation, the conceptual framework (resources-functiontransformation-cost) guiding this study is presented in Figure 1. According to resource-based theory, we know that every scenic area has unique resources, which help attractions obtain competitiveness and advantages in the tourism market. As outlined above, these resources include core resources and supporting resources. However, the ecosystem as a core resource is complex and not easily measured. As noted above, to make it easier to measure and operate, a function analysis was employed to divide the ecosystem into five functions and then convert them into three kinds of value (social-cultural, economic, and ecological) in which the supporting resources (such as human resources and capital) participated.

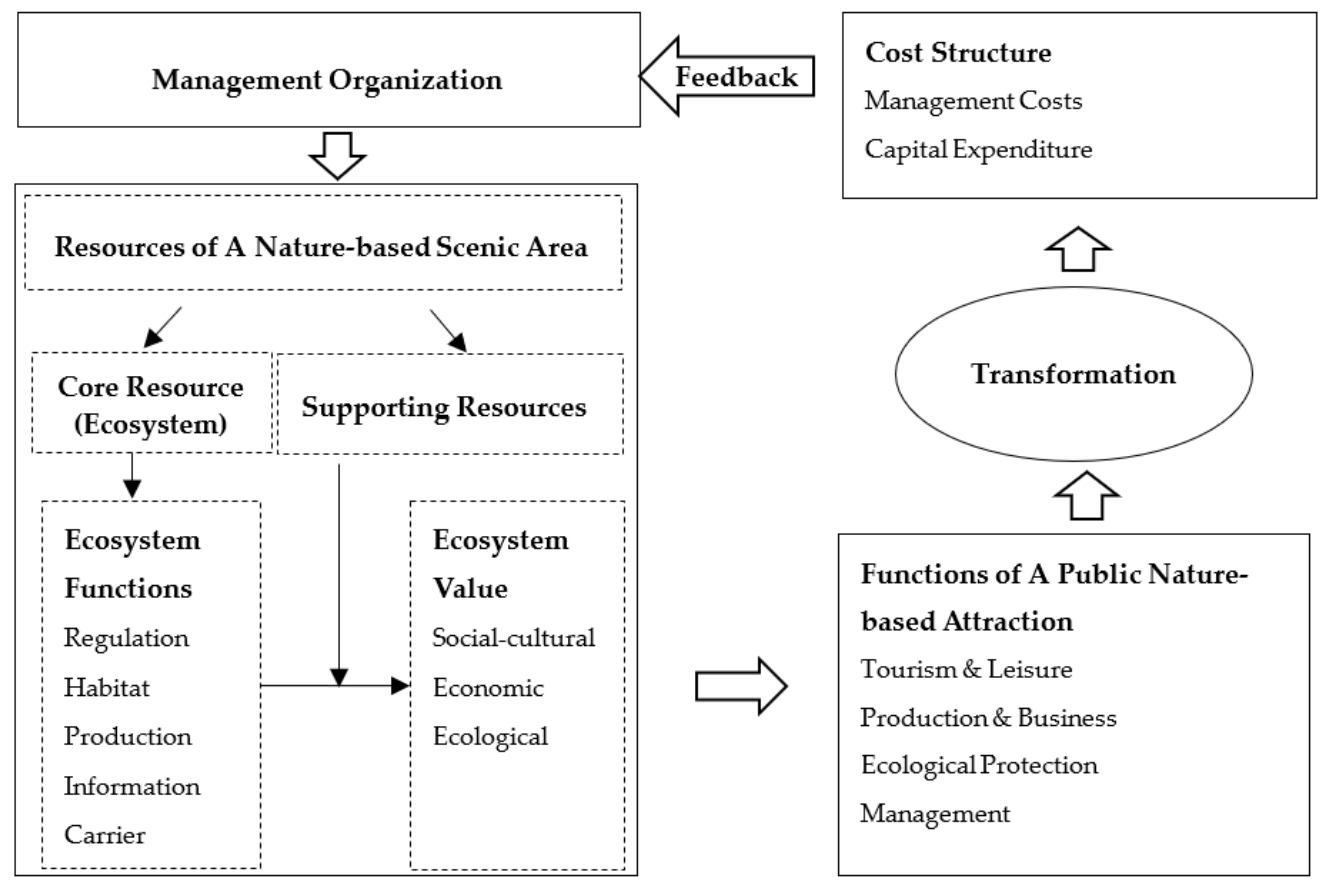

Figure 1. Research framework of resources-function-transformation-cost in a nature-based scenic area. Source: own draft based on the function analysis and resource-based theory.

On the basis of this division and conversion, four functions of a nature-based scenic area are identified, implying the multi-functional attribute of a scenic area, as managers making use of and combining all kinds of resources attempt to realize their operating goals. That is, different proportions of management costs and capital expenditure are required to realize scenic area functions. Next, the organization adjusts strategic decisions through cost-structure analysis, shown by the feedback line in Figure 1. Management organization is that which completes the conversion from resources to scenic area functions and provides tourists with products and services. In the process, the organization has to integrate and utilize internal resources, especially capital resources, which will incur costs.

Furthermore, to some extent, resources owned by an organization depend on its stage of development, because each stage concentrates on different resources, then leading to different management actions [37]. In other words, the use of core resources changes in different stages. In this study, we call this 'transformation'. For example, at first, managers directly obtain products from the ecosystem (this being the production function of the ecosystem) and sell them to generate income. Then, with market development, consumers eventually look for a change in products. Under this case scenario, they will have to turn to using other ecosystem resources to meet market demand, such as those relating to other functions of the ecosystem such as spiritual enrichment, cognitive development, recreation, 
and aesthetic experience in order to develop tourism to attract future visitors and generate income. In this way, 'transformation' takes place. Transformation is realized following structure of functions changes, which means that strategic objectives change sufficiently, causing a change in cost. We will discuss this aspect of cost-structure and function analysis in the context of SNFP in Part 4 of this paper. Before doing so, we will first outline the research methodology.

\section{Methodology and Results}

In conducting this research, the longitudinal case study method was adopted. The reasons for doing so are as follows. Firstly, this article seeks to solve the 'what' and 'why' problems, and there is little empirically based theory that would help us understand the implications of strategies employed by practitioners. Therefore, the longitudinal case study method is suitable for solving such problems [52,53]. Secondly, the case study can answer questions related to the above research framework, and, in turn, the method aids understanding of the framework [54]. Thirdly, this approach assists the advancement of our understanding of the changes and evolution of the relationship between transformation and cost structure [55].

\subsection{Methods}

\subsubsection{Study Area}

Shanghai Sheshan National Forest Park (SNFP), a national AAAA class public naturebased scenic area, is located in Songjiang District, an ancient city in the western suburbs of Shanghai (Figure 2). It covers an area of 401 hectares and is $30 \mathrm{~km}$ from the city center. It is the only natural mountain forest park in Shanghai. The nine peaks and twelve mountains were formed about 70 million years ago in the late Mesozoic era. Liangzhu culture (approx. 4300 years BCE) and Guangfulin culture (approx. 4000 BCE), both of which are early human cultures that developed in this region, are the origins of Shanghai's ancient cultural heritage.

The functions and business model of SNFP have changed several times since its establishment in 1988, which is suitable to answer the longitudinal questions of this research (more details on the history of SNFP are outlined below). Furthermore, the entrance fee of SNFP has now been abolished, reflecting the recent trend of promoting equality of public access as a public good (in line with the central government's reform agenda as outlined in the introduction). Specifically, SNFP opened four parks for tourism and leisure: East Sheshan Park, West Sheshan Park, Tianma Mountain Park, and Xiaokunshan Park, accounting for $54 \%$ of the total area. The rest of SNFP is under strict conservation protection. The East and West Sheshan Parks receive more than $90 \%$ of all visitors to SNFP every year. Entry to these two parks was made free of charge on 20 September 2008 and 30 December 2010, respectively. This indicates that the trend towards free entry was already in process at this time but did not reach a nation-wide significance until more recently.

The management organization of SNFP is Shanghai Songjiang Forestry Station (SSFS), a public institution fully funded by the local Songjiang district government. SNFP operates under the auspices of the Shanghai Sheshan National Tourism Resort Management Committee. In practice, SNFP receives investment from both SSFS and the management committee. Subsequently, the costs of SNFP include not only all of the costs of SSFS but also those of the management committee.

\subsubsection{Data Source}

'Triangular verification' was carried out by combining the primary data (directly obtained data) and secondary data (indirectly obtained data) to ensure data reliability [53]. The primary data were mainly derived from interviews. The research team interviewed managers from the Songjiang District Tourism Bureau (1 time), Shanghai Sheshan National Tourism Resort Committee (1 time), and SSFS (2 times) from October 2017 to April 2018. A total of $270 \mathrm{~min}$ of audio recording was converted into a 39,384 Chinese character text. 


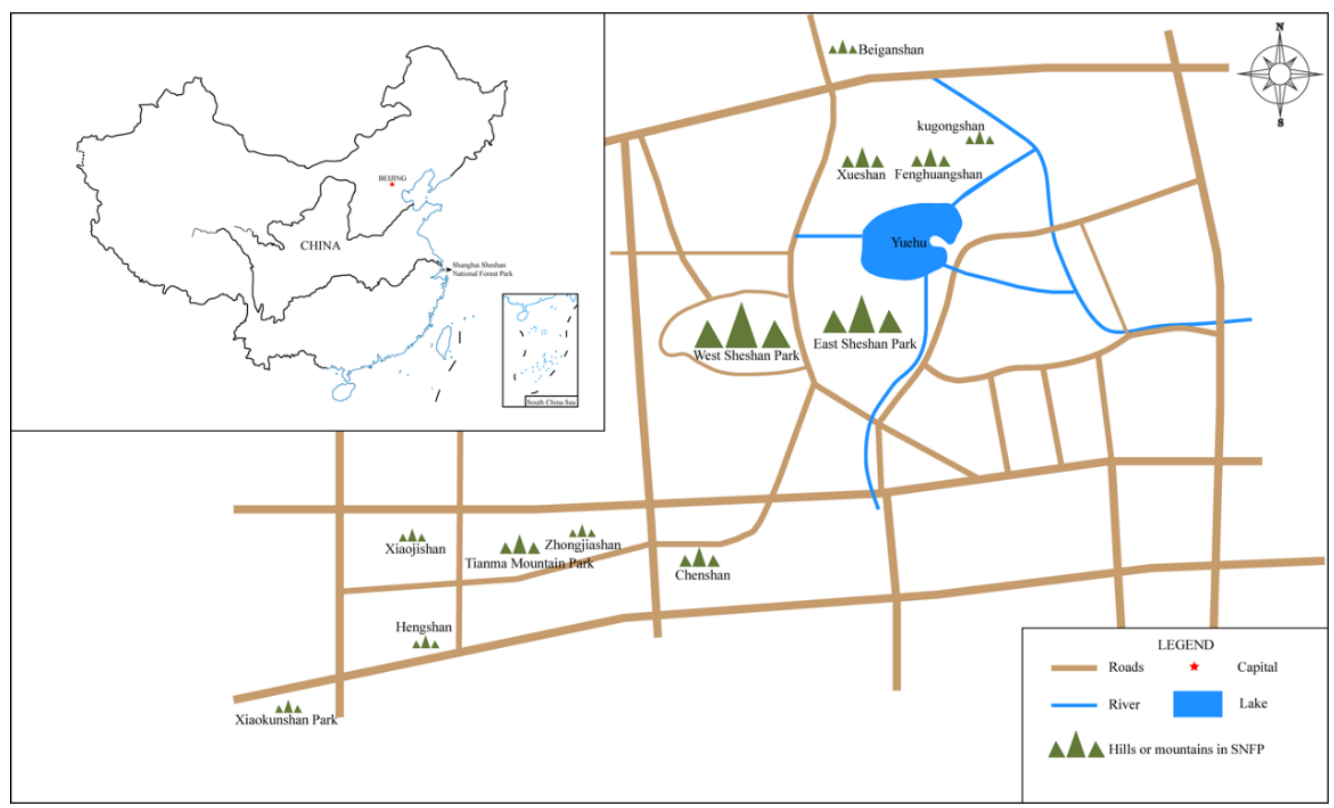

Figure 2. Location of SNFP. Note: Chenshan was transferred to Shanghai Chenshan Botanical Garden Station in 2008 and is no longer under the jurisdiction of the SNFP. Therefore, SNFP now contains 11 hills and mountains, as shown in the figure. Source: own draft.

The secondary data were various, including journals and publications about SNFP, information on the official website of SNFP, unpublished textual materials, such as Sheshan Culture and The 20th Anniversary of Beautiful Sheshan:1993-2013 provided by SSFS, and the Sheshan National Tourism Resort Chronicle provided by the management committee. The secondary data also included annual reports of SSFS (2014-2018) obtained from the official website of Shanghai Institutions Online (http:/ / www.sydjsh.cn), annual budget and financial statements (2014-2018) downloaded from the official website of the Shanghai Government (http:/ / www.songjiang.gov.cn), and cost information acquired from bidding items presented by the official website of Shanghai Government Procurement (http:// www.zfcg.sh.gov.cn). Notably, all costs in this study were converted to year 1988 RMB (the starting date for the research period) by using the local CPI index for the reported year.

\subsection{Results}

Based on the interview data, four stages of development of SNFP were identified and named according to the main goals of each stage as follows: Stage 1, 'production' (1988-1992); Stage 2, 'tourism' (1993-2002); Stage 3, 'transition' (2003-2010); and Stage 4, 'protection' (2011-2018). Through the longitudinal case study of SNFP, it was found that the resources used, the function structure, and the cost structure all underwent tremendous changes within the four stages.

\subsubsection{Cost Structure of Each Stage in SNFP}

In the production stage (1988-1992), because of its attractive natural resources, the Sheshan Scenic Zone Administration was established by Songjiang Government to develop natural tourism and accept tourists in 1988. The local government and committee invested heavily in attractions such as the Journey to the West Maze, cable car and other facilities to attract tourists. This was the beginning in China of the first stage of urban tourism and leisure development since the onset of reforms initiated in the late 1970s. To be clear, tourism and leisure functions in SNFP appeared during this period. However, since the organization was established based on the SSFS, it continued to sell products obtained directly from the ecosystem, such as bamboo shoots and dead wood, and to engage in planting and reforestation. Hence, in this stage, SNFP revenue was mainly derived from 
the utilization of products from the ecosystem. The major functions were management (M), production and business (P\&B), and then tourism and leisure (T\&L). Table 1 presents the amount and proportion of costs for this stage. Around 75.64\% (RMB 767,400) of the whole cost was capital expenditure, of which 94.63\% (RMB 726,200) was used in the construction of tourism facilities. The cost proportion of each function was $4.87 \%(\mathrm{M}), 16.24 \%$ (P\&B), and $78.89 \%$ (T\&L). M and P\&B functions invested more in management, $100 \%$ and $75 \%$, respectively, while T\&L functions more on capital expenditure (90.73\%).

Table 1. Functions and cost structure of SNFP; 10,000 of 1988 RMB.

\begin{tabular}{|c|c|c|c|c|c|c|c|}
\hline \multirow{2}{*}{ Stages } & \multirow{2}{*}{ Functions } & \multicolumn{2}{|c|}{ Management Costs } & \multicolumn{2}{|c|}{ Capital Expenditure } & \multicolumn{2}{|c|}{ Mean } \\
\hline & & RMB & $\%$ & RMB & $\%$ & RMB & $\%$ \\
\hline \multirow{4}{*}{$\begin{array}{l}\text { Production } \\
(1988 \sim 1992)\end{array}$} & Management (M) & 4.94 & 100 & - & - & 4.94 & 4.87 \\
\hline & Production and Business (P\&B) & 12.36 & 75.00 & 4.12 & 25.00 & 16.48 & 16.24 \\
\hline & Tourism and Leisure (T\&L) & 7.42 & 9.27 & 72.62 & 90.73 & 80.04 & 78.89 \\
\hline & Sum & 24.72 & 24.36 & 76.74 & 75.64 & 101.46 & 100 \\
\hline \multirow{5}{*}{$\begin{array}{c}\text { Tourism } \\
(1993 \sim 2002)\end{array}$} & Management (M) & 31.02 & 100 & - & - & 31.02 & 6.41 \\
\hline & Production and Business (P\&B) & 17.73 & 75 & 5.91 & 25.00 & 23.64 & 4.88 \\
\hline & Tourism and Leisure (T\&L) & 70.90 & 18.48 & 312.74 & 81.52 & 383.64 & 79.27 \\
\hline & Ecological protection (EP) & 13.29 & 29.12 & 32.35 & 70.88 & 45.64 & 9.43 \\
\hline & Sum & 132.95 & 27.47 & 351 & 72.53 & 483.95 & 100 \\
\hline \multirow{4}{*}{$\begin{array}{l}\text { Transition } \\
(2003 \sim 2010)\end{array}$} & Management (M) & 49.71 & 100 & - & - & 49.71 & 11.53 \\
\hline & Tourism and Leisure (T\&L) & 89.48 & 45.29 & 108.11 & 54.71 & 197.59 & 45.84 \\
\hline & Ecological protection (EP) & 59.65 & 32.46 & 124.13 & 67.54 & 183.78 & 42.63 \\
\hline & Sum & 198.84 & 46.13 & 232.24 & 53.87 & 431.08 & 100 \\
\hline \multirow{4}{*}{$\begin{array}{l}\text { Protection } \\
(2011 \sim 2018)\end{array}$} & Management (M) & 204.93 & 94.76 & 11.34 & 5.24 & 216.27 & 28.47 \\
\hline & Tourism and Leisure (T\&L) & 54.45 & 41.49 & 76.79 & 58.51 & 131.24 & 17.27 \\
\hline & Ecological protection (EP) & 239.99 & 58.21 & 172.27 & 41.79 & 412.26 & 54.26 \\
\hline & Sum & 499.37 & 65.73 & 260.39 & 34.27 & 759.76 & 100 \\
\hline
\end{tabular}

Source: Authors' own calculations. Note: The value in the table is the average annual cost of each stage. The unit of cost is RMB10,000 a year. '-' means the value was not reported or negligibly small.

At the beginning of the tourism stage (1993-2002), due to its unique forest ecology, the SNFP was awarded the title of 'National Forest Park' in 1993 by the National Forestry and Grassland Administration. The new title marked the establishment of a conservation zone and tourist attraction, and a new stage of tourism development. SNFP then opened officially under its new title in the same year. From that time on, SNFP mainly focused on tourism activities instead of obtaining products from the ecosystem. In other words, as the market for forestry products decreased and timber logging was controlled by the government in the late 1990s, its focus shifted from production to tourism in order to improve competitiveness. Meanwhile, in cooperation with the local government, SSFS continued to develop scenic areas (with a total investment of approximately RMB 11.86 million) and tourism projects (total investment of nearly RMB 19.41 million), meaning that information and carrier functions were used in this stage instead of production functions of the ecosystem. Thus, P\&B functions of SNFP dropped dramatically as a proportion of total costs from $16.24 \%$ to $4.88 \%$. T\&L functions, by contrast, experienced a rapid increase from RMB 804,000 to 3.84 million. Notably, the last three years of this stage saw a big growth in EP functions costs, mostly of the construction of firefighting facilities. On the whole, most of the costs were related to capital expenditure $(72.53 \%)$, the same as the previous stage, and mainly in T\&L functions (RMB 3.13 million, 89.1\%). In a similar fashion to the previous stage, $M$ and $\mathrm{P} \& \mathrm{~B}$ functions invested more in management, whereas T\&L and EP functions focused more on capital expenditure.

As a result of the decrease in park and facilities demand and the ecological destruction caused by the pine wood nematode (Bursaphelenchus xylophilus) that caused pine wilt disease, at the end of the tourism stage, the strategic goal of SSFS was shifted from tourism to ecological protection. As the director of the committee said, 
"The era of mass tourism and self-driving tours brought huge challenges to the park. Attractiveness of the forest was limited and demand of tourist facilities decreased. The facilities also damaged the ecosystem. Since 2003 we had to close and remove the facilities and set about focusing on protection. For example, a tourism attraction named Bird Park was closed and cleared away in 2008. (This attraction) generated too much bird dung which was destructive to the soil. Also, the net built to define the range of bird activities damaged the forest undercanopy thereby had an impact on the entire ecology."

SNFP thus came to the third stage of transition from tourism to protection (20032010). These eight years saw the disappearance of P\&B functions and a sharp rise of EP functions, up to $42.63 \%$. This almost corresponded to T\&L functions (45.84\%). All functions focused mostly on capital expenditure except for $M$ functions. Likewise, SNFP invested a large proportion (53.87\%) in capital items. The gap between management and capital costs narrowed.

Free admission to East and West Sheshan Park (the main parts and attractions of the park) was implemented in 2008 and 2010, respectively. From then on, the revenue of SSFS shifted from self-support to total subsidy granted by the local government. This marked a new development stage of SNFP, that is, the protection stage (2011-2018). As the director of SSFS said,

"SNFP was selected to open for free because of its unique natural forest, known as the best in Shanghai. With the development of the local economy, more emphasis was placed by the local government on ecology and more pursuit of ecotourism than ever before. After free admission, SSFS was converted into a public institution fully funded by the local government, and our work focus is totally on the management of scenic spots, ecology protection, and fire prevention. All of these activities are for public welfare."

Moreover, the director of the committee said,

"Before, the ticket was set to control the flow of visitors and cover the cost. Later, with the development of local economy, the government gradually considered that it had the ability to bear the cost and that the resource should be shared with the citizens for free. Therefore, SNFP was charged free in 2008 and 2010."

During the final stage, major functions of SNFP thoroughly changed from T\&L to EP $(54.26 \%)$, regulation and habitat functions of the ecosystem were focused, and ecological value was used, following the shift in admission fee. M and T\&L functions were consistent with previous stages, with most costs on management $(94.76 \%)$ and capital expenditure $(58.51 \%)$, respectively. However, the cost of EP functions turned to management costs $(65.73 \%)$ from capital expenditure in the previous two stages. It is worth noting that instead of capital expenditure, management costs accounted for $65.73 \%$ (RMB 4,99 million) of the total cost. Furthermore, RMB 1.72 million (66.17\%) of total capital expenditure cost was of the construction of EP, and most of the overall management costs (RMB 2.4 million, 48.06\%) were also on EP functions.

\subsubsection{Evolution of Cost Structure}

Combined internal factors such as reduced resource attractiveness and ecosystem destruction, along with external factors such as industrial structure adjustment, policy changes, economic growth, and changes in resident consumption habits, SNFP underwent four stages and changes of functions and cost structure. In 1982, Zhangjiajie National Forest Park, located in Hunan province, southwest of China, was approved by the central government to be the first national forest park in China. From then on, the ecological value of forests was paid more attention and put to good use throughout China. From 1988, because of this rise of eco-tourism in China, SNFP carried out tourism activities based on some tourist facilities under construction mainly invested in by the local government. More capital expenditures than management costs were spent on investment in tourism facilities, though SSFS focused on production and business. Next, SNFP officially launched tourist activities as a national forest park since 1993, meaning it had the ability to draw 
tourists with good infrastructure as well as protect the ecosystem. Priority was placed on attracting tourists and then business and protection during this stage. A number of tourism projects were invested in to attract tourists. Then, the invasion of the pine wood nematode (Bursaphelenchus xylophilus) occurred, along with the degradation of the ecosystem in the early years of the 21st century and a decline of visitors from 2001 to 2003 (from 1.25 million in 2001 to 0.78 million in 2002 and 0.55 million in 2003). SSFS, therefore, had to turn to ecological protection and restoration since 2003. During this stage, tourism projects were removed, and ecological facilities were heavily invested in. With financial support from the local government, SNFP abolished its entrance fee in 2008, and SSFS was totally funded by the government.

In terms of changes in cost structure, in general, differences between management costs and capital expenditure narrowed. Furthermore, the management cost occupied a dominant position in the fourth stage. The cost of M and EP functions increased gradually, while the cost of $\mathrm{P} \& \mathrm{~B}$ and $\mathrm{T} \& \mathrm{~L}$ functions declined. Several trends can be observed in Figure 3. In summary, the use of funds has changed significantly over the years. Most of the capital expenses were expended in T\&L functions during the first two stages but in EP functions during the stages of transition and protection, implying that in the early stages of functions implementation more costs were of capital items, while more were of management costs in the latter stages. Additionally, most management costs were in $P \& B$ functions in the first stage, T\&L functions in second and third stages, and EP functions in the fourth stage. To put it another way, management costs of SNFP accounted for an increasing amount of the total cost during the last three decades, from $24.36 \%, 27.47 \%$, and $46.13 \%$ to $65.73 \%$ (Table 1). From the definition of management costs, we know that these costs are recurrent and cannot be reduced in the short term. It is even harder for a public institution to reduce this part of the cost, which means cost elasticity is lower and lower [20]. These changes reflect the focus and strategy relating to attractions.

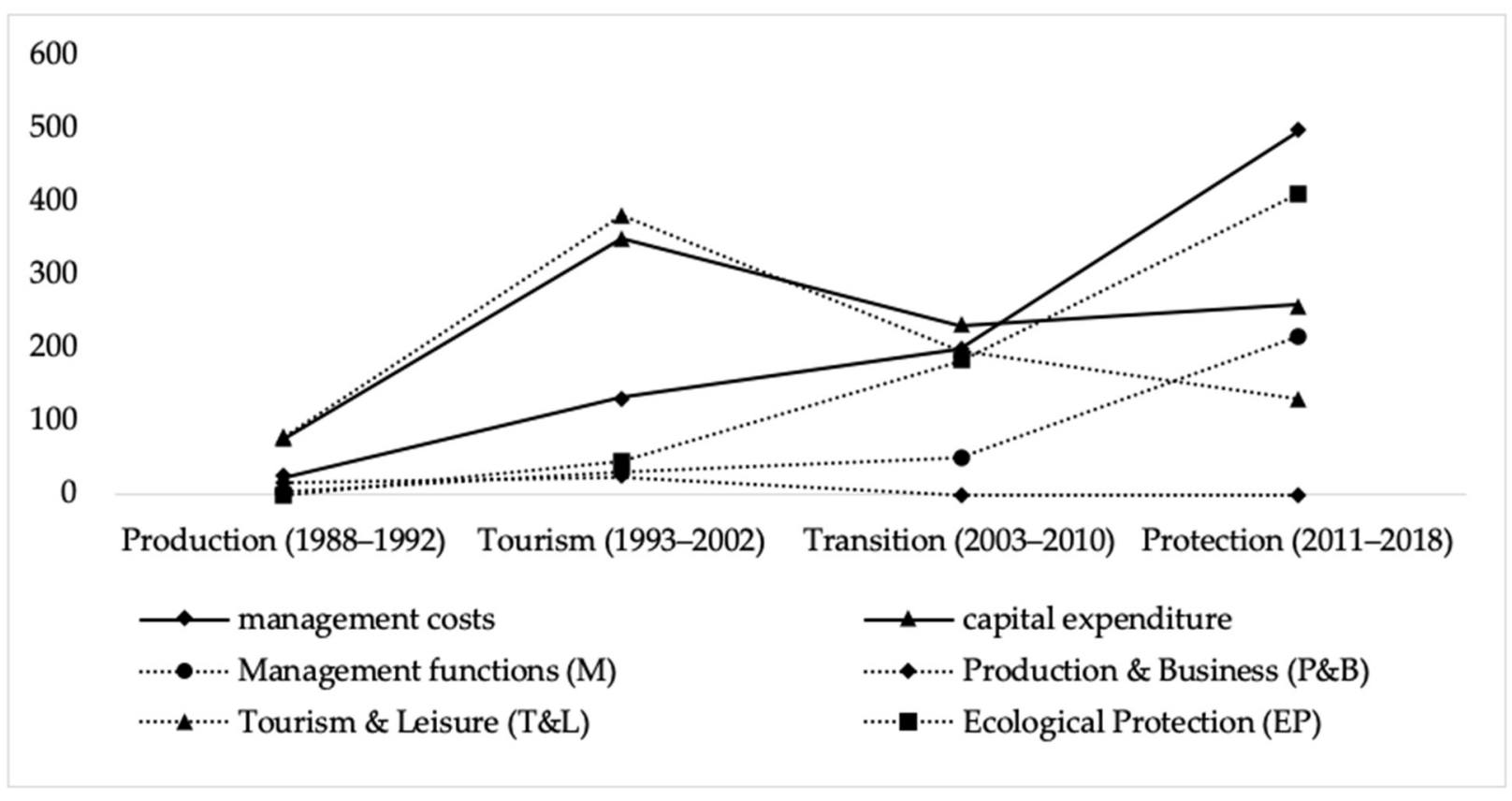

Figure 3. Functions and cost structure of SNFP from 1988 to 2018; 10,000 of RMB (1988). Note: The ordinate represents the amount of cost. Source: Authors' own elaboration.

The function structure of SNFP was unstable during all four stages. This was due to different functions of the ecosystem, leading to the disappearance of $\mathrm{P} \& \mathrm{~B}$ functions, emergence of EP functions, weakness of T\&L functions (declining from $79 \%$ to $17.27 \%$ ), and increase in $\mathrm{M}$ functions (increasing from $4.87 \%$ to $24.47 \%$ ). Nevertheless, the structure 
of functions seemed to stabilize gradually in the last period, with $\mathrm{M}$, T\&L, and EP functions co-existing. The stability of the cost structure of functions is also different. The cost structure of all functions was relatively stable, except for EP functions. During the four stages, costs of $\mathrm{M}$ and $\mathrm{P} \& \mathrm{~B}$ functions were mainly management costs. T\&L functions were focused on capital expenditure, while EP functions were capital expenditure in the first three stages and management costs in the fourth stage.

The structure of cost changed consistently with cost. From Figure 3, we can see that, firstly, the trend of capital expenditure was roughly the same as T\&L functions, with a surge in the second stage and a plummet in the last two stages. The amount of cost of T\&L functions dominated the whole consumption in SNFP in the first three stages. Moreover, most of the costs were capital expenditure in T\&L functions. Secondly, the trend of management costs changed with $\mathrm{M}$ and EP functions. Because $\mathrm{M}$ and EP functions invested much more in management, and as the significance of EP functions increased, the importance of management costs was enhanced.

\section{Discussion}

Facing all kinds of stresses, many public attractions are seeking to transform. In this context, it is therefore important to analyze the transformation and its impact on finance in scenic areas. For public attractions, cost management is especially important, because most of them do not focus on generating revenue. Only a handful of scholars have recognized this phenomenon. For instance, from the stakeholder perspective, Li et al. (2020) discussed who will bear the cost after transformation [8]. However, what will happen to the cost structure has not been adequately explored by researchers, even though it is a top concern of practitioners. In focusing on the question of "how does the transformation of a scenic area take place and what will the impact be on the cost structure", this study referred to resource-based theory and a function analysis in the longitudinal case study of SNFP. The current study presents a framework "resource-function-transformation-cost" to explain the relationship between transformation and cost structure.

\subsection{Theoretical Contributions}

The present study contributes to the tourist attraction management literature in a number of ways. First, from an ontology perspective, in terms of resource-based theory, resources are the driving factors for managers to make decisions to move forward [35,36]. Following this line of reasoning, the study theoretically contributed to the literature by developing a conceptual framework to unpack the relationship between transformation and cost in public nature-based attractions. The origin of transformation comes from resources owned by attractions and different combinations of resources lead to different function structures (management activities), causing changes in cost structure over time. Consistent with prior literature in the accounting field, managerial resource choices lead to changes in cost structure [20]. From this view, in contrast to nature-based attractions, cost structures of cultural attractions are different because of the dependent resources (the core resource for nature-based attractions is the ecosystem, whilst for cultural-based attractions, it is heritage, culture, collections, etc.), which would lead to different managerial actions and then resulting in different cost structures. For example, culture-based attractions may spend more on management, while most nature-based attractions may invest more in capital items. Therefore, the conceptual framework can serve as a foundation for future financial studies of public tourist attractions.

Second, as a nature-based scenic area, its core resource is the ecosystem, the complexity of which can be converted to several functions by using function analysis, which is also a useful tool to overcome resource operation difficulties. Meanwhile, multifunctional attributes of nature-based scenic areas are presented. Apart from preventing natural hazards [56], as forest parks, they engaged in the timber economy during the last century and also provided access to the natural environment for a variety of leisure activities [57]. Consequently, functions changed with the development of tourist sites due to the change of 
resource concentration. It is intuitive that different functions have different cost structures, but there is a lack of research studying the explicit path between them. The current longitudinal case study revealed the path and situation in different stages.

Third, cost is an essential element of financial sustainability. Previous studies mainly focus on the price structure $[6,12,14,15,18,58]$ and cost bearers $[8,12]$. In this study, we enrich the cost study of attractions to cost structure from a dynamic perspective with the aid of resource-based theory and function analysis. As researchers in accounting studies have shown us, the cost structure is positively related to attraction performance [49]. Moreover, the management costs of SNFP accounted for an increasing total cost during the last three decades. It implies that the elasticity of cost structure is increasingly lower in attractions, which is disadvantageous [20,51]. Prior literature has examined the positive relationship between cost elasticity and a firm's future performance, indicating higher cost elasticity presenting better performance [49]. This implies that the findings would influence managerial decision-making to take whatever actions are required for the next step in the transformation, as shown by the feedback line in the research framework.

\subsection{Practical Implications}

The cost analysis provides detailed suggestions for managers to allocate resources rationally. As the results show, when there is a transformation, functions changed first because of the resources reallocated, and then the changes in costs followed. That is, transformation would have a significant impact on cost structure, which should be paid attention to by managers and policy makers. For managers, when they want to change strategic direction for financial sustainability, our conceptual framework may give them cause to rethink certain aspects to achieve cost competitiveness, such as which functions will cost less and which will cost more. Through adjusting functions using a different combination of resources, managers may achieve better cost structure and performance. The government also often provides financial aids (such as government funding) to public nature-based attractions [59], meaning that adjustment of the cost structure of public attractions leads to the reconsideration of the amount of government budget. The idea can be applied worldwide, not just to China. Meanwhile, it is also very helpful to decide on the oriented strategy for a new established tourist site built by the government.

In addition, with rising labor costs [60] and management costs dominating a greater share, managers have to take action to cut down management costs, such as by introducing volunteer management mechanisms like in the National Park System in the United States and in some nature-based scenic areas in China.

\section{Conclusions}

In the light of resource-based theory and function analysis, this paper developed a framework centered around cost and transformation to answer this question: how does cost change after transformation? The results showed that because of function change after transformation, the cost structure would also change. In our setting, during production, tourism, and transition stages, capital expenditure dominated the total cost, while in the protection stage, management costs prevailed, implying that the elasticity of cost structure is low, which is disadvantageous to the attractions' future performance. Additionally, the structure of functions tended to be stable, and the cost structure of $M, P \& B$, and T\&L functions did not change much, while EP functions changed from capital expenditure to management costs.

Although some conclusions are drawn from the present research, there are still a few limitations. First, as it is hard to obtain complete records of financial items [61], especially other organizations invested in SNFP, the total cost data may be underestimated, which would have the possibility of influencing the proportion of capital expenditure. In order to overcome this weakness, adopting a large number of samples to interpret the question statistically is a future research goal. Advanced quantitative tools such as theoretical derivation using game theory are also a good method. Second, as stated in management ac- 
counting studies, both internal and external factors would change cost structure [20,49-51]. The present research emphasizes the internal aspect. Yet, environmental conditions, as external factors such as demand uncertainty, are also very important [62], which should be taken into account in future studies. Lastly, the tourism industry, as a mixed economy, includes public, private, and non-profit sectors [63]. A common division among them is modes of ownership, funding, and social control [64]. Public sectors have multiple goals, while private ones are profit-oriented, which could lead to different strategies even though they have similar resources $[63,65,66]$. To be specific, public sectors tend to focus more on protection and public welfare [8], meaning management costs would likely dominate total costs, as in the fourth stage of SNFP. In order to test and examine the results, ownership should also be considered [67]. The context of other countries should also be incorporated in future studies.

Author Contributions: Conceptualization, J.-Y.L.; methodology, J.-Y.L.; investigation, J.-Y.L., H.Q. and Q.-J.L.; data curation, J.-Y.L.; writing-original draft preparation, J.-Y.L.; writing-review and editing, Q.-J.L. and G.S. All authors have read and agreed to the published version of the manuscript.

Funding: The research received funding by National Natural Science Foundation of China, grant number 41571116, and Shanghai University of Finance and Economics, grant number CXJJ-2017-359. The funders had no role in the design of the study; in the collection, analyses, or interpretation of data; in the writing of the manuscript; or in the decision to public results.

Institutional Review Board Statement: Restrictions apply to the availability of these data. Data was mainly obtained from Shanghai Sheshan National Forest Park and Shanghai Sheshan National Tourism Resort Management Committee, and data are available from the corresponding author with the permission of Sheshan National Forest Park. The data were approved by supervision committee of National Natural Science Foundation of China (41571116, approved 24 April 2020).

Informed Consent Statement: Not applicable.

Data Availability Statement: The data presented in this study are available on request from the corresponding author. The data are not publicly available due to the data also forms part of an ongoing study.

Acknowledgments: Authors are thankful to the three anonymous reviewers for their insightful and helpful suggestions.

Conflicts of Interest: The authors declare no conflict of interest.

\section{References}

1. McKercher, B. Managing heritage resources as tourism products. Asia Pac. J. Tour. Res. 2004, 9, 255-266. [CrossRef]

2. Hughes, M.; Carlsen, J. The business of cultural heritage tourism: Critical success factors. J. Heritage Tour. 2010, 5, 17-32. [CrossRef]

3. Banerjee, O.; Cicowiez, M.; Ochuodho, T.; Masozera, M.; Wolde, B.; Lal, P.; Dudek, S.; Alavalapati, J.R.R. Financing the sustainable management of Rwanda's protected areas. J. Sustain. Tour. 2018, 26, 1381-1397. [CrossRef]

4. Roberts, R.M.; Jones, K.W.; Seidl, A.; Ek, A.; Smith, H. Conservation finance and sustainable tourism: The acceptability of conservation fees to support the Tambopata National Reserve, Peru. J. Sustain. Tour. 2016, 25, 1353-1366. [CrossRef]

5. Reynisdottir, M.; Song, H.; Agrusa, J. Willingness to pay entrance fees to natural attractions: An Icelandic case study. Tour. Manag. 2008, 29, 1076-1083. [CrossRef]

6. Zou, S. National park entrance fee increase: A conceptual framework. J. Sustain. Tour. 2020, 28, 2099-2117. [CrossRef]

7. Buckley, R. Pay to Play in Parks: An Australian Policy Perspective on Visitor Fees in Public Protected Areas. J. Sustain. Tour. 2003, 11, 56-73. [CrossRef]

8. Li, Q.; Quan, H.; Wang, L.-E. Beneficiaries of free admission to scenic areas: A cost-benefit analysis of scenic areas for public welfare from the perspective of stakeholders. Tour. Manag. Perspect. 2020, 35. [CrossRef]

9. Knapman, B.; Stoeckl, N. Recreation User Fees: An Australian Empirical Investigation. Tour. Econ. 1995, 1, 5-15. [CrossRef]

10. Frazee, S.; Cowling, R.; Pressey, R.; Turpie, J.; Lindenberg, N. Estimating the costs of conserving a biodiversity hotspot: A case-study of the Cape Floristic Region, South Africa. Biol. Conserv. 2003, 112, 275-290. [CrossRef]

11. Prendergast, J.R.; Quinn, R.M.; Lawton, J.H. The Gaps between Theory and Practice in Selecting Nature Reserves. Conserv. Biol. 1999, 13, 484-492. [CrossRef]

12. Sun, X.H. A study on different ways of cost reimbursement between the Chinese and the American tourist attractions. Bus. Manag. J. 2014, 10, 117-127. 
13. Armsworth, P.R.; Cantú-Salazar, L.; Parnell, M.; Davies, Z.G.; Stoneman, R. Management costs for small protected areas and economies of scale in habitat conservation. Biol. Conserv. 2011, 144, 423-429. [CrossRef]

14. Duan, Q.F.; Wu, S. A study on the characteristics of public scenic spot and its pricing costs. Price Theory Pract. 2017, 11, 91-94.

15. Gao, S. On the reduction of expenses at scenic areas and simplification of price-fixing method. Tour. Trib. 2009, $24,60-66$.

16. Pellinen, J. Making price decisions in tourism enterprises. Int. J. Hosp. Manag. 2003, 22, 217-235. [CrossRef]

17. Zhu, X.H.; Fu, J.H. Research on Ticked Price Optimization of Tourist Attractions; Social Sciences Academic Press: Beijing, China, 2017.

18. Zou, S.; Petrick, J.F. Testing the Effect of Price Framing on Nonresidents' Perceptions of Dual Pricing in State Parks: An Application of Prospect Theory. Leis. Sci. 2019, 1-22. [CrossRef]

19. Anderson, S.W. Managing Costs and Cost Structure throughout the Value Chain: Research on Strategic Cost Management; Elsevier: Amsterdam, The Netherlands, 2006; pp. 481-506.

20. Holzhacker, M.; Krishnan, R.; Mahlendorf, M.D. Unraveling the Black Box of Cost Behavior: An Empirical Investigation of Risk Drivers, Managerial Resource Procurement, and Cost Elasticity. Account. Rev. 2015, 90, 2305-2335. [CrossRef]

21. Aboody, D.; Levi, S.; Weiss, D. Managerial incentives, options, and cost-structure choices. Rev. Account. Stud. 2017, 23, 422-451. [CrossRef]

22. Ministry of Culture and Tourism of China. Available online: https://www.mct.gov.cn/whzx/whyw/201810/t20181001_835209 .htm (accessed on 1 October 2018).

23. CamareroM, C.; Garrido, M.J.; Vicente, E. How cultural organizations' size and funding influence innovation and performance: The case of museums. J. Cult. Econ. 2011, 35, 247-266. [CrossRef]

24. Whitelaw, P.A.; King, B.E.; Tolkach, D. Protected areas, conservation and tourism-Financing the sustainable dream. J. Sustain. Tour. 2014, 22, 584-603. [CrossRef]

25. UNWTO World Tourism Barometer, May 2020-Special Focus on the Impact of COVID-19; UNWTO: Madrid, Spain, 2020.

26. Ministry of Culture and Tourism of China. Available online: https://www.mct.gov.cn/preview/special/8830/qykyal/202003/t2 0200330_852203.htm (accessed on 3 March 2020).

27. Li, P.; Ryan, C.; Cave, J. Chinese rural tourism development: Transition in the case of Qiyunshan, Anhui, 2008-2015. Tour. Manag. 2016, 55, 240-260. [CrossRef]

28. Stamboulis, Y.; Skayannis, P. Innovation strategies and technology for experience-based tourism. Tour. Manag. 2003, 24, 35-43. [CrossRef]

29. Chen, Y.-S.; Wu, S.-T. An exploration of actor-network theory and social affordance for the development of a tourist attraction: A case study of a Jimmy-related theme park, Taiwan. Tour. Manag. 2021, 82, 104206. [CrossRef]

30. Butler, R. The concept of a tourist area cycle of evolution: Implications for management of resources. Can. Geogr. 1980, 24, 5-12. [CrossRef]

31. Zhong, L.; Deng, J.; Xiang, B. Tourism development and the tourism area life-cycle model: A case study of Zhangjiajie National Forest Park, China. Tour. Manag. 2008, 29, 841-856. [CrossRef]

32. Law, J.; Singleton, V. Object Lessons. Organization 2005, 12, 331-355. [CrossRef]

33. Buckley, R.; Guitart, D.; Shakeela, A. Contested surf tourism resources in the Maldives. Ann. Tour. Res. 2017, 64, 185-199. [CrossRef]

34. Ahuja, G.; Katila, R. Where do resources come from? The role of idiosyncratic situations. Strat. Manag. J. 2004, 25, 887-907. [CrossRef]

35. Barney, J. Firm Resources and Sustained Competitive Advantage. J. Manag. 1991, 17, 99-120. [CrossRef]

36. Barney, J.B.; Ketchen, D.J.; Wright, M. The Future of Resource-Based Theory. J. Manag. 2011, 37, 1299-1315. [CrossRef]

37. Sirmon, D.G.; Hitt, M.A.; Ireland, R.D.; Gilbert, B.A. Resource Orchestration to Create Competitive Advantage. J. Manag. 2011, 37, 1390-1412. [CrossRef]

38. Young, G.; Smith, K.G.; Grimm, C.M.; Simon, D. Multimarket Contact and Resource Dissimilarity: A Competitive Dynamics Perspective. J. Manag. 2000, 26, 1217-1236. [CrossRef]

39. Draft, R. Organization Theory and Design; West: New York, NY, USA, 1983.

40. Crouch, G.; Ritchie, J. Tourism, Competitiveness, and Societal Prosperity. J. Bus. Res. 1999, 44, 137-152. [CrossRef]

41. Hueting, R. The economic functions of the environment. Evaluation of environmental effects of transport. In Proceedings of the International Roundtable Organized by PTRC Education and Research Services Ltd., Hague, The Netherlands, 19-20 June 1995.

42. Hueting, R.; Reijnders, L.; De Boer, B.; Lambooy, J.; Jansen, H. The concept of environmental function and its valuation. Ecol. Econ. 1998, 25, 31-35. [CrossRef]

43. De Groot, R.S. Environmental functions as a unifying concept for ecology and economics. Environmentalist 1987, 7, 105-109. [CrossRef]

44. De Groot, R.S. A Functional Ecosystem Evaluation Method as a Tool in Environmental Planning and Decision Making; Agricultural University: Amsterdam, The Netherlands, 1986.

45. De Groot, R.S. Function-analysis and valuation as a tool to assess land use conflicts in planning for sustainable, multi-functional landscapes. Landsc. Urban Plan. 2006, 75, 175-186. [CrossRef]

46. De Groot, R.S. Functions of Nature: Evaluation of Nature in Environmental Planning, Management and Decision-Making; WoltersNoordhoff: Groningen, The Netherlands, 1992.

47. De Groot, R.S.; Wilson, M.A.; Boumans, R.M.J. A typology for the classification, description and valuation of ecosystem functions, goods and services. Ecol. Econ. 2002, 41, 393-408. [CrossRef]

48. Green, J.M.; Burgess, N.D.; Green, R.E.; Madoffe, S.S.; Munishi, P.K.; Nashanda, E.; Turner, R.K.; Balmford, A. Estimating management costs of protected areas: A novel approach from the Eastern Arc Mountains, Tanzania. Biol. Conserv. 2012, 150, 5-14. [CrossRef]

49. Bhojraj, S.; Bloomfield, R.; Jang, Y.; Yehuda, N. Cost Structure, Operating Leverage and CDS Spreads. Account. Rev. 2020. [CrossRef]

50. Kallapur, S.; Eldenburg, L. Uncertainty, Real Options, and Cost Behavior: Evidence from Washington State Hospitals. J. Account. Res. 2005, 43, 735-752. [CrossRef] 
51. Banker, R.D.; Byzalov, D.; Plehn-Dujowich, J.M. Demand Uncertainty and Cost Behavior. Account. Rev. 2013, 89, 839-865. [CrossRef]

52. Paroutis, S.; Heracleous, L. Discourse revisited: Dimensions and employment of first-order strategy discourse during institutional adoption. Strat. Manag. J. 2013, 34, 935-956. [CrossRef]

53. Yin, R.K. Case Study Research: Design and Methods, 5th ed.; Sage Publications: Los Angeles, CA, USA, 2014.

54. Dickson, T.; Darcy, S.; Walker, C. A Case of Leveraging a Mega-Sport Event for a Sport Tourism Legacy: A Prospective Longitudinal Case Study of Whistler Adaptive Sports. Sustainability 2020, 13, 170. [CrossRef]

55. Langley, A.; Smallman, C.; Tsoukas, H.; Van De Ven, A.H. Process Studies of Change in Organization and Management: Unveiling Temporality, Activity, and Flow. Acad. Manag. J. 2013, 56, 1-13. [CrossRef]

56. Notaro, S.; Paletto, A. The economic valuation of natural hazards in mountain forests: An approach based on the replacement cost method. J. For. Econ. 2012, 18, 318-328. [CrossRef]

57. Mattsson, L.; Li, C.-Z. How do Different Forest Management Practices Affect the Non-timber Value of Forests-An Economic Analysis. J. Environ. Manag. 1994, 41, 79-88. [CrossRef]

58. Zou, G.Y.; Liu, M.Y.; He, J.M. One-ticket or two-part tariff? An analysis on the vertical restrictions for managing public scenic spots in China. Tour. Trib. 2015, 30, 60-71.

59. Eagles, P.F. Fiscal implications of moving to tourism finance for parks: Ontario Provincial Parks. Manag. Leis. 2013, 19, 1-17. [CrossRef]

60. Liu, D.J. The rise of labor cost and economic development transition. J. Lanzhou Commer. Coll. 2011, 27, 48-54.

61. McCrea-Strub, A.; Zeller, D.; Sumaila, U.R.; Nelson, J.; Balmford, A.; Pauly, D. Understanding the cost of establishing marine protected areas. Mar. Policy 2011, 35, 1-9. [CrossRef]

62. Emerton, L.; Bishop, J.; Thomas, L. Sustainable Financing of Protected Areas: A Global Review of Challenges and Options. In Sustainable Financing of Protected Areas: A Global Review of Challenges and Options; International Union for Conservation of Nature: Gland, Switzerland, 2006.

63. Andersson, T.D.; Getz, D. Tourism as a mixed industry: Differences between private, public and not-for-profit festivals. Tour. Manag. 2009, 30, 847-856. [CrossRef]

64. Perry, J.L.; Rainey, H.G. The Public-Private Distinction in Organization Theory: A Critique and Research Strategy. Acad. Manag. Rev. 1988, 13, 182-201. [CrossRef]

65. Assaf, A.G.; Tsionas, M.G.; Gillen, D. Measuring firm performance: Differentiating between uncontrollable and controllable bad outputs. Tour. Manag. 2020, 80, 104107. [CrossRef]

66. Hvidman, U.; Andersen, S.C. Impact of Performance Management in Public and Private Organizations. J. Public Adm. Res. Theory 2013, 24, 35-58. [CrossRef]

67. Andersson, M. Assessing non-industrial private forest owners' attitudes to risk: Do owner and property characteristics matter? J. For. Econ. 2012, 18, 3-13. [CrossRef] 